Bài báo khoa học

\title{
Đánh giá biến động đường bờ biển Thị xã Vĩnh Châu tỉnh Sóc Trăng bằng phương pháp ảnh viễn thám
}

\author{
Lê Minh Hậu ${ }^{1}$, Huỳnh Thị Cẩm Hồng², Trần Tuyết Loan², Đinh Văn Duy ${ }^{2 *}$, Trần Văn \\ T. $\dot{\mathbf{y}}^{2}$
}

${ }^{1}$ Ban quản lý Dự án 2 tỉnh Sóc Trăng; haum4220004@gstudent.ctu.edu.vn

${ }^{2}$ Khoa Công nghệ, Trường Đại học Cần Thơ; htchong@ctu.edu.vn; loanb1705837@student.ctu.edu.vn; dvduy@ctu.edu.vn; tvty@ctu.edu.vn

*Tác giả liên hệ: dvduy@ctu.edu.vn; Tel.: +84-906975999.

Ban Biên tập nhận bài: 02/10/2021; Ngày phản biện xong: 17/11/2021; Ngày đăng bài: $25 / 01 / 2022$

Tóm tắt: Diễn biến đường bờ biển là nguồn dữ liệu quan trọng để đánh giá mức độ xói lở và bồi tụ của bãi biển. Trong các phương pháp khảo sát diễn biến đường bờ biển, phân tích ảnh viễn thám là một phương pháp giúp thu thập số liệu vị trí đường bờ biển một cách nhanh chóng và hầu như miễn phí. Nghiên cứu này sử dụng phương pháp phân tích ảnh viễn thám để đánh giá biến động đường bờ biển thị xã Vĩnh Châu tỉnh Sóc Trăng giai đoạn 2006-2020 để tìm ra vận tốc xói lở, bồi tụ đường bờ tại các mặt cắt dọc theo đường bờ biển cũng như tính toán thay đổi thể tích bãi biển $(\Delta \mathrm{V})$. Kết quả phân tích cho thấy một phần đường bờ biển khu vực thị xã Vĩnh Châu tỉnh Sóc Trăng (từ cống số 2 đến cống số 3 ) bị xói lở nghiêm trọng trong giai đoạn 2006-2020 với bề rộng rừng ngập mặn suy giảm khoảng 70-140 m giai đoạn 2006-2014 và 10-50 m giai đoạn 2014-2020. Vận tốc xói lở đường bờ biển lớn nhất bằng $11,68 \mathrm{~m} /$ năm và vận tốc suy giảm thể tích bãi biển tại các mặt cắt dọc theo đường bờ biển khu vực nghiên cứu dao động trong khoảng 3.000-7.000 m³/năm. Các kết quả của nghiên cứu có thể làm cơ sở để các cấp quản lý có giải pháp bảo vệ và phục hồi bãi biển một cách hợp lý.

Từ khóa: Vĩnh Châu Sóc Trăng; Ảnh viễn thám; vận tốc thay đổi đường bờ; thay đổi thể tích bãi biển; mô hình một đường.

\section{Mở đầu}

Quan sát biến động đường bờ biển có ý nghĩa quan trọng về mặt kinh tế xã hội trong công tác quản lý đường bờ biển như đề ra các giải pháp chống sạt lở bờ biển hay thiết lập hành lang an toàn cho các công trình xây dựng dọc theo bờ biển [1-2]. Mặc dù khái niệm “đường bờ" được định nghĩa đơn giản là ranh giới giữa vùng đất và vùng nước, việc xác định vị trí đường bờ biển trong thực tế lại rất phức tạp [3] vì vị trí đường bờ biển luôn thay đổi và tạo thành một vùng chuyển tiếp giữa vùng đất và nước biển [4]. Các phương pháp thu thập dữ liệu vị trí đường bờ bao gồm phân tích các bản đồ [5], đo đạc, khảo sát hiện trường [6], sử dụng thiết bị bay không người lái [7] hoặc lắp đặt hệ thống camera quan sát biến động 
đường bờ biển một cách liên tục [8]. Các phương pháp này có chung hạn chế về không gian và thời gian. Hơn nữa, chi phí để thực hiện các phương pháp khảo sát đo đạc hiện trường để thu thập dữ liệu trong một thời đoạn dài rất tốn kém. Đối với các nước đang phát triển, nguồn vốn cho việc khảo sát thường rất hạn chế [9], vì vậy, không thể tiến hành khảo sát đường bờ biển trong một khoảng thời gian dài và trên một phạm vi rộng lớn [10]. Vì vậy, cần có một phương pháp hiệu quả về mặt kinh tế trong nghiên cứu bờ biển ở Việt Nam. Một trong các phương pháp giúp quan sát diễn biến đường bờ biển một cách nhanh chóng và tiết kiệm chi phí là phương pháp phân tích ảnh viễn thám với nguồn dữ liệu ảnh có thể tải về miễn phí [11]. Do đó, mục tiêu của nghiên cứu này là nhằm ứng dụng công nghệ phân tích ảnh viễn thám trong nghiên cứu biến động vị trí đường bờ biển và tính toán vận tốc xói bồi của bờ biển. Sau đó, thay đổi thể tích bãi biển tại các mặt cắt dọc theo đường bờ biển sẽ được tính toán dựa trên tốc độ xói bồi của bờ biển tại các mặt cắt.

Khu vực nghiên cứu là một phần đường bờ biển thuộc thị xã Vĩnh Châu tỉnh Sóc Trăng. Tỉnh Sóc Trăng có phần đất liền nằm từ $9^{\circ} 14^{\prime} \mathrm{N}-9^{\circ} 56^{\prime} \mathrm{N}$ vĩ độ Bắc và $105^{\circ} 34^{\prime} \mathrm{E}-106^{\circ} 18^{\prime} \mathrm{E}$ kinh độ Đông với đường bờ biển trải dài $72 \mathrm{~km}$. Vùng ven biển tỉnh Sóc Trăng chịu ảnh hưởng của dòng chảy từ sông Hậu, chế độ triều biển Đông và dòng chảy ven bờ [12]. Trong những năm gần đây, hiện tượng xói lở bờ biển trước các tuyến đê ven biển Sóc Trăng ngày càng trở nên nghiêm trọng. Xói lở không chỉ xuất hiện dọc theo các tuyến đê biển mà còn xuất hiện ở cả các đoạn đường bờ biển có rừng ngập mặn [13]. Cụ thể, tại thị xã Vĩnh Châu tỉnh Sóc Trăng, xói lở bờ biển và mất dần diện tích rừng ngập mặn đang diễn ra nghiêm trọng tại khu vực giáp ranh với tỉnh Bạc Liêu với hiện tượng chủ yếu là hạ thấp bãi trước chân các tuyến đê. Cùng với hiện tượng hạ thấp bãi làm gia tăng độ sâu cột nước trước đê, chiều cao sóng trước đê cũng tăng thêm từ $0,45-0,5 \mathrm{~m}$. Tại các khu vực rừng ngập mặn bị suy thoái, độ sâu xói lở lên đến 1-1,5 m [13].

Nghiên cứu này tập trung phân tích diễn biến vị trí một phần đường bờ biển đang bị xói lở nghiêm trọng tại thị xã Vĩnh Châu tỉnh Sóc Trăng (từ cống số 2 đến cống số 3 ) trong giai đoạn 2006-2020 (Hình 1) bằng công nghệ phân tích ảnh viễn thám. Từ chuỗi số liệu về vị trí đường bờ qua các năm, vận tốc xói bồi đường bờ biển và vận tốc thay đổi thể tích bãi biển khu vực này sẽ được tính toán dựa vào phương pháp hồi quy tuyến tính và lý thuyết mô hình một đường. Vận tốc xói bồi và thay đổi thể tích bãi biển là các yếu tố đóng vai trò quan trọng và cần được làm rõ để có thể đưa ra được các giải pháp bảo vệ bờ biển một cách căn cơ và bền vững.

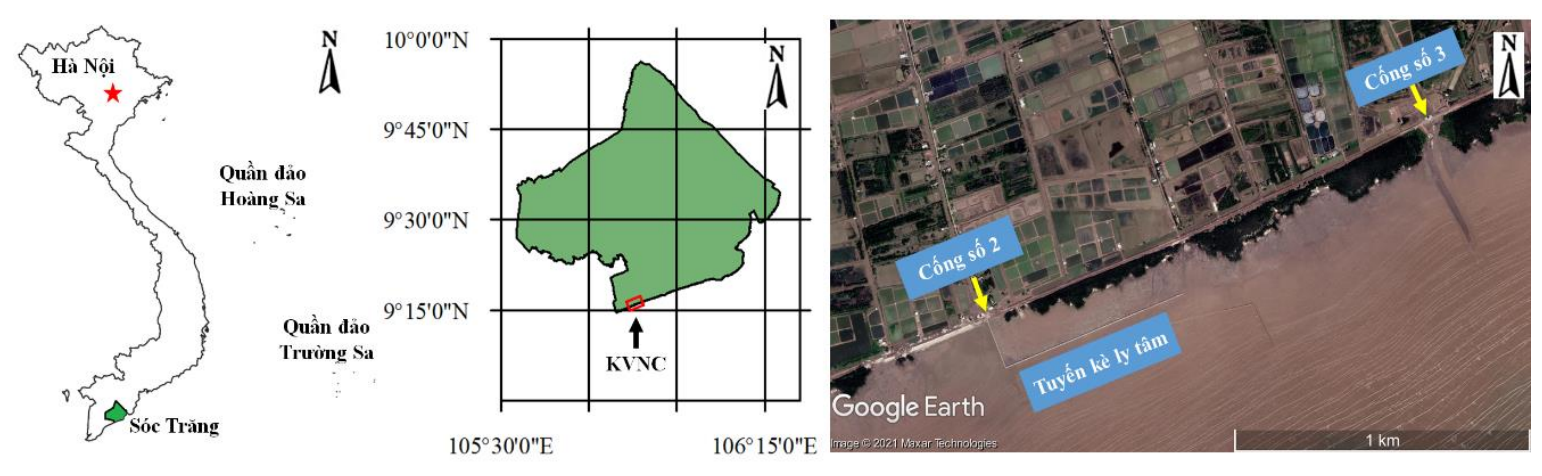

Hình 1. Khu vực nghiên cứu. 


\section{Phương pháp nghiên cứu}

Phương pháp nghiên cứu được mô tả như trong sơ đồ trên Hình 2. Các ảnh viễn thám tải về bằng công cụ Google earth không cùng khung hình học nên sẽ được nắn chỉnh và tiến hành giải đoán đường bờ. Từ số liệu vị trí đường bờ, vận tốc xói bồi bờ biển sẽ được tính toán dựa vào phương pháp hồi quy tuyến tính. Các giá trị về chiều sâu vận chuyển bùn cát $\left(\mathrm{D}_{\mathrm{C}}\right)$ và chiều cao thềm bãi $\left(\mathrm{D}_{\mathrm{B}}\right)$ cũng được tính toán dựa vào các số liệu mặt cắt địa hình bãi biển KVNC được thu thập trong các nghiên cứu trước đây. Từ số liệu vận tốc xói bồi bãi biển, chiều sâu vận chuyển bùn cát $\left(\mathrm{D}_{\mathrm{C}}\right)$ và chiều cao thềm bãi $\left(\mathrm{D}_{\mathrm{B}}\right)$, vận tốc thay đổi thể tích bãi biển $(\Delta \mathrm{V})$ sẽ được tính toán dựa trên lý thuyết mô hình một đường (one-line model). Chi tiết từng bước tính toán sẽ được trình bày trong các bước tiếp theo.

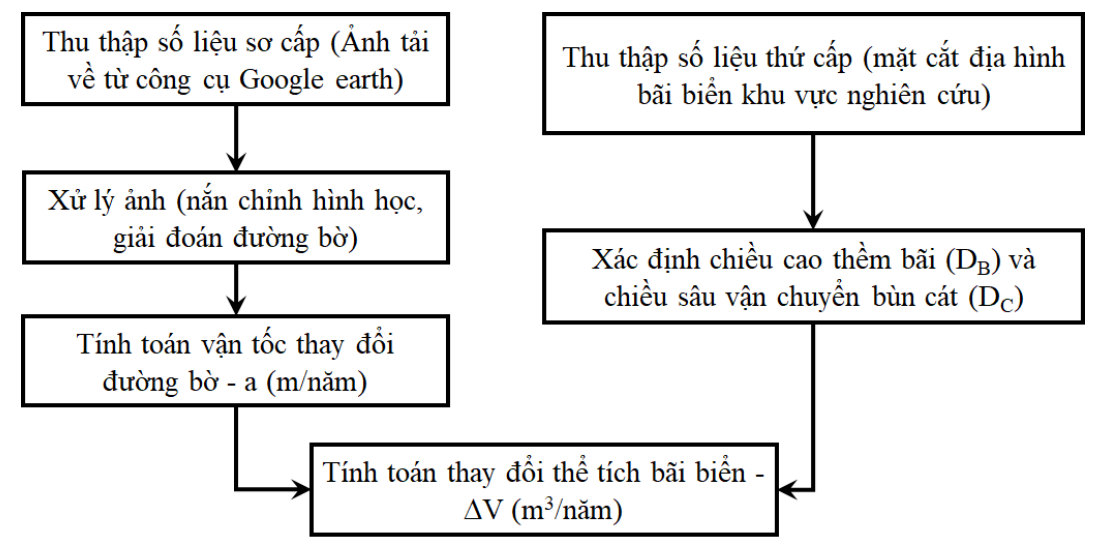

Hình 2. Sơ đồ cấu trúc các bước nghiên cứu.

\subsection{Phân tích ảnh viên thám}

Các ảnh chất lượng cao được tải về từ phần mềm Google Earth (ảnh Google Earth) được sử dụng để phân tích diễn biến đường bờ biển khu vực nghiên cứu. Các ảnh Google Earth có độ phân giải $1,0 \mathrm{~m}$ và được trình bày trong Bảng 1 .

Bảng 1. Số liệu ảnh Google Earth.

\begin{tabular}{cccc}
\hline Thòi gian & Nguồn ảnh & Độ phân giải (m) & Hệ tọa độ \\
\hline $04 / 12 / 2006$ & Maxar Technologies & $1,0 \mathrm{~m}$ & UTM \\
$08 / 04 / 2014$ & CNES/Airbus & $1,0 \mathrm{~m}$ & UTM \\
$09 / 06 / 2017$ & CNES/Airbus & $1,0 \mathrm{~m}$ & UTM \\
$09 / 03 / 2018$ & CNES/Airbus & $1,0 \mathrm{~m}$ & UTM \\
$15 / 02 / 2019$ & Maxar Technologies & $1,0 \mathrm{~m}$ & UTM \\
$14 / 11 / 2020$ & Maxar Technologies & $1,0 \mathrm{~m}$ & UTM \\
\hline
\end{tabular}

Vì ảnh tải về từ phần mềm Google Earth không cùng khung hình học nên các ảnh này được nắn chỉnh hình học bằng chức năng Registration trong bộ công cụ Map của ENVI trước khi tiến hành phân tích giải đoán đường bờ. Các điểm khống chế được sử dụng để tiến hành nắn chỉnh hình học các ảnh. Sơ đồ các điểm khống chế được trình bày trên Hình 3 . Sai số trung bình bình phương (RMSE) được sử dụng để đánh giá độ chính xác của việc nắn chỉnh ảnh theo công thức:

$$
\text { RMSE }=\sqrt{\sum_{\mathrm{i}=1}^{\mathrm{n}} \frac{\left(\widehat{\mathrm{y}}_{\mathrm{i}}-\mathrm{y}_{\mathrm{i}}\right)^{2}}{\mathrm{n}}}
$$

Trong đó $\mathrm{y}_{\mathrm{i}}$ là tọa độ điểm khống chế thứ $\mathrm{i}$; $\hat{y}_{\mathrm{i}}$ là giá trị ước đoán bằng mô hình hồi quy tuyến tính tại điểm khống chế thứ $i$, và $\bar{y}$ là giá trị trung bình cộng của tất cả các giá trị $\mathrm{y}_{\mathrm{i}}$. 


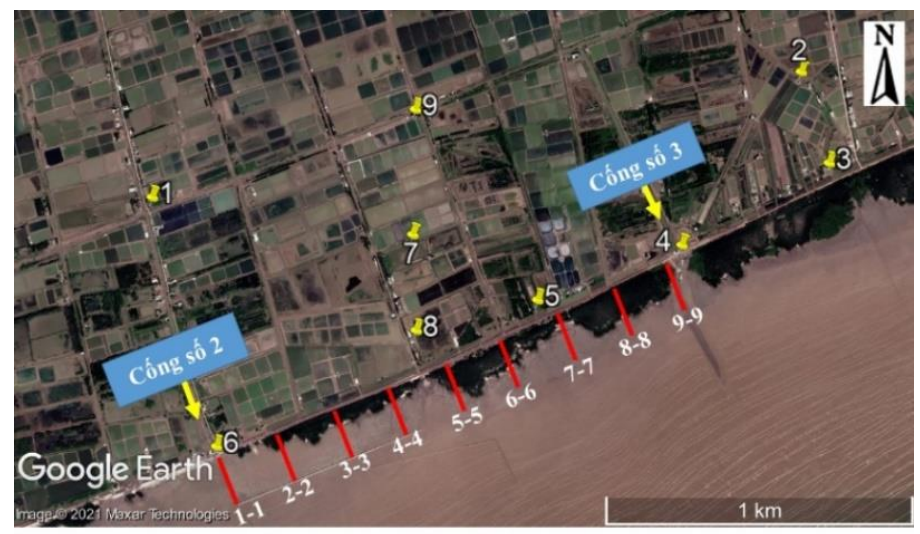

Hình 3. Sơ đồ các điểm khống chế mặt đất (GCP).

Phương pháp chiết xuất đường bờ của ảnh Google Earth và sai số của phương pháp này được tham khảo trong nghiên cứu của [14-16]. Nghiên cứu này sử dụng định nghĩa đường bờ là đai rừng ngập mặn nên không xét đến ảnh hưởng của dao động mực nước đến vị trí đường bờ.

\subsection{Tính toán vận tốc thay đổi đường bờ}

Vận tốc thay đổi đường bờ (shoreline change rate) là một trong các chỉ số được sử dụng phổ biển nhất trong các nghiên cứu về bờ biển [17]. Vận tốc thay đổi đường bờ được định nghĩa là sự thay đồi của vị trí đường bờ tại một mặt cắt vuông góc với đường bờ theo thời gian. Sự thay đổi này có thể là dài hạn (long-term) hoặc ngắn hạn (short-term). Trong đó, vận tốc thay đổi đường bờ theo thời đoạn dài hạn có thể tính bằng thập kỷ hoặc thế kỷ trong khi vận tốc thay đổi đường bờ ngắn hạn có thể tính bằng sự thay đồi vị trí đường bờ theo mùa hoặc thậm chí theo ngày. Theo [17], một trong các phương pháp phổ biến trong tính toán vận tốc thay đổi đường bờ là phương pháp hồi quy tuyến tính (LR). Đặc điểm của phương pháp pháp này dựa trên nguyên tắc thống kê sử dụng tất cả các điểm dữ liệu có sẵn trong chuỗi dữ liệu về vị trí đường bờ. Trong đó, độ dốc của đường thẳng hồi quy chính là vận tốc thay đổi đường bờ. Công thức của đường thẳng hồi quy được thể hiện như sau:

$$
\mathrm{y}=\mathrm{a} \times \mathrm{t}+\mathrm{b}
$$

Trong đó $\mathrm{y}(\mathrm{m})$ là vị trí đường bờ; a là hệ số góc của đường thẳng hồi quy và là tốc độ thay đổi vị trí đường bờ ( $\mathrm{m} / \mathrm{năm})$; $\mathrm{t}$ là thời gian (năm) và $\mathrm{b}$ là giao điểm giữa đường thẳng hồi quy và trục tung.

Để có cơ sở đánh giá sự phù hợp của mô hình tuyến tính đối với chuỗi số liệu vị trí đường bờ, hệ số xác định $\mathrm{R}^{2}$ được tính toán như sau [18]:

$$
\mathrm{R}^{2}=1-\frac{\mathrm{SS}_{\text {res }}}{\mathrm{SS}_{\text {tot }}}
$$

Với $\mathrm{SS}_{\text {res }}$ và $\mathrm{SS}_{\mathrm{tot}}$ lần lượt là tổng các độ lệch bình phương phần dư và tổng các độ lệch bình phương toàn bộ, được tính toán như sau:

$$
\begin{aligned}
& \mathrm{SS}_{\text {res }}=\sum_{\mathrm{i}}\left(\mathrm{y}_{\mathrm{i}}-\hat{\mathrm{y}}_{\mathrm{i}}\right)^{2} \\
& \mathrm{SS}_{\mathrm{tot}}=\sum_{\mathrm{i}}\left(\mathrm{y}_{\mathrm{i}}-\overline{\mathrm{y}}\right)^{2}
\end{aligned}
$$

Trong các công thức trên, $\mathrm{y}_{\mathrm{i}}$ là vị trí đường bờ năm thứ $\mathrm{i}, \hat{\mathrm{y}}_{\mathrm{i}}$ là giá trị ước đoán bằng mô hình hồi quy tuyến tính tại năm thứ $i, \bar{y}$ là giá trị trung bình cộng của tất cả các giá trị $\mathrm{y}_{\mathrm{i}}$. Như vậy ta có công thức tính $\bar{y}$ như sau: 


$$
\overline{\mathrm{y}}=\frac{\sum_{\mathrm{i}} \mathrm{y}_{\mathrm{i}}}{\mathrm{n}}
$$

Với $\mathrm{n}$ là tổng số lượng vị trí đường bờ thu thập được tại một mặt cắt trong khoảng thời gian từ năm 2006 đến năm 2020.

Trong nghiên cứu này, các mặt cắt được phân đoạn theo khoảng cách $200 \mathrm{~m}$ dọc theo đường bờ biển khu vực nghiên cứu từ cống số 2 đến cống số 3 để tiến hành đo đạc vị trí đường bờ và tính toán vận tốc thay đổi đường bờ như trong Hình 3 . Khoảng cách giữa mặt cắt $8-8$ và $9-9$ là $120 \mathrm{~m}$. Đường bờ biển ngày $04 / 12 / 2006$ được chọn làm đường cơ sở để tính toán giá trị vận tốc thay đổi đường bờ.

Trong nghiên cứu này, các mặt cắt được phân đoạn theo khoảng cách $200 \mathrm{~m}$ dọc theo đường bờ biển khu vực nghiên cứu từ cống số 2 đến cống số 3 để tiến hành đo đạc vị trí đường bờ và tính toán vận tốc thay đổi đường bờ như trong Hình 3 . Khoảng cách giữa mặt cắt 8-8 và 9-9 là $120 \mathrm{~m}$. Đường bờ biển ngày $04 / 12 / 2006$ được chọn làm đường cơ sở để tính toán giá trị vận tốc thay đổi đường bờ.

\subsection{Tính toán vận tốc thay đổi thể tích bãi biển}

Vận tốc thay đổi thể tích bãi biển được tính toán từ vận tốc thay đổi đường bờ với giả thiết rằng đường bờ giữ nguyên hình dạng khi dịch chuyển theo phương ngang bờ và phạm vi dịch chuyển theo một chiều sâu không đổi (mô hình một đường) (Hình 4) [19-21]:

$$
\mathrm{D}=\mathrm{D}_{\mathrm{B}}+\mathrm{D}_{\mathrm{C}}
$$

Trong đó $\mathrm{D}_{\mathrm{B}}$ là chiều cao thềm bãi $(\mathrm{m})$ và $\mathrm{DC}$ là chiều sâu vận chuyển bùn cát tới hạn (m).

Từ các giả thiết trên ta có công thức tính thay đổi thể tích bãi biển giữa hai mặt cắt liên tiếp như sau:

$$
\Delta \mathrm{V}=\mathrm{D} \times \Delta \mathrm{y} \times \Delta \mathrm{x}
$$

Trong đó $\Delta y$ là giá trị trung bình vận tốc thay đổi đường bờ giữa 2 mặt cắt liên tiếp $(\mathrm{m} / \mathrm{năm}), \Delta \mathrm{x}$ là khoảng cách giữa 2 mặt cắt liên tiếp $(\mathrm{m}), \mathrm{t}$ là thời gian (năm), $\Delta \mathrm{V}$ là vận tốc thay đổi thể tích bãi biển $\left(\mathrm{m}^{3} /\right.$ năm) và $\mathrm{D}=\mathrm{D}_{\mathrm{B}}+\mathrm{D}_{\mathrm{C}}(\mathrm{m})$.

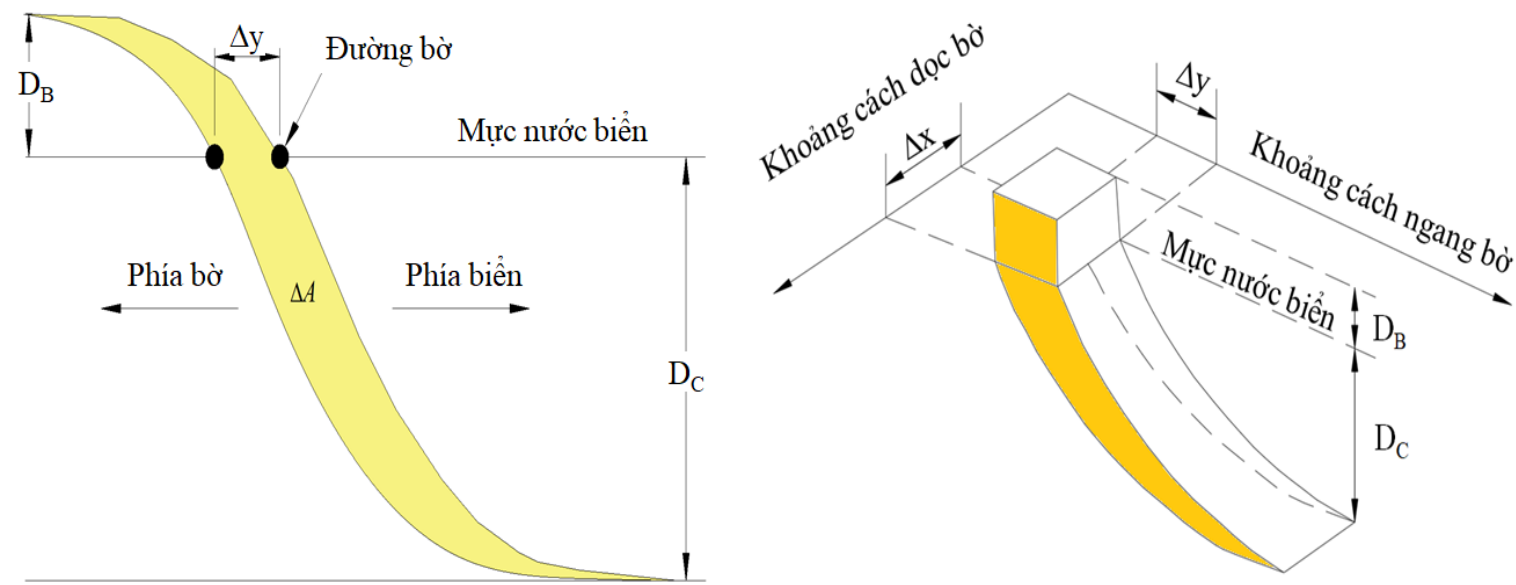

Hình 4. Mô hình tính toán vận tốc thay đổi thể tích bãi biển.

Giá trị vận tốc thay đổi đường bờ tại các mặt cắt từ 1-1 đến 9-9 như trên Hình 3 sẽ được sử dụng để tính toán vận tốc thay đổi thể tích bãi biển $(\Delta \mathrm{V})$ trong giai đoạn 2006-2020. Khoảng cách giữa các mặt cắt được chọn là $\Delta \mathrm{x}=200 \mathrm{~m}$ ngoại trừ khoảng cách giữa mặt cắt 8-8 và 9-9 là $120 \mathrm{~m}$. Chiều cao thềm bãi và chiều sâu vận chuyển bùn cát tại khu vực nghiên 
cứu được tính toán dựa vào mặt cắt địa hình bãi biển quan trắc qua các năm [22]. Theo nghiên cứu [13], D tại khu vực nghiên cứu có giá trị trong khoảng $3 \mathrm{~m}$.

\section{Kết quả và thảo luận}

\subsection{Phân tích ảnh viễn thám}

Sai số nắn chỉnh hình học ảnh được trình bày như trong Bảng 2. Có thể nhận thấy sai số nắn chỉnh các ảnh đều nhỏ hơn $1,0 \mathrm{~m}$. Ảnh chụp ngày 14/11/2020 được chọn làm ảnh gốc để nắn chỉnh các ảnh còn lại nên không có sai số nắn chỉnh hình học cho ảnh chụp ngày 14/11/2020. Ảnh chụp năm 2006 cách đây khá lâu nên chỉ tìm được 7 điểm khống chế mặt đất cho ảnh năm 2006.

Bảng 2. Sai số nắn chỉnh hình học ảnh.

\begin{tabular}{ccc}
\hline Thòi gian & Số điểm khống chế mặt đất & RMSE $(\mathbf{m})$ \\
\hline $04 / 12 / 2006$ & 7 & 0,47 \\
$08 / 04 / 2014$ & 9 & 0,50 \\
$09 / 06 / 2017$ & 9 & 0,61 \\
$09 / 03 / 2018$ & 9 & 0,48 \\
$15 / 02 / 2019$ & 9 & 0,50 \\
$14 / 11 / 2020$ & 9 & - \\
\hline
\end{tabular}

\subsection{Vận tốc thay đổi vị trí đường bò biển}

Vị trí đường bờ tại các mặt cắt được đo đạc qua các năm để tính toán vận tốc thay đổi đường bờ. Sự thay đổi vị trí đường bờ theo các mặt cắt từ cống số 2 đến cống số 3 trong giai đoạn 2006-2020 được trình bày như trong Bảng 3 và Hình 5 . Đường bờ ngày 12/04/2006 được chọn làm đường cơ sở nên vị trí đường bờ tại các mặt cắt trong ngày 12/04/2006 đều bằng 0 . Trên Hình 5 chỉ trình bày vị trí đường bờ của các năm 2006, 2014, và 2020 để tiện cho việc quan sát sự thay đổi vị trí đường bờ. Có thể nhận thấy đường bờ biển khu vực nghiên cứu bị xói lở nghiêm trọng từ năm 2006 đến 2020 . Cụ thể, bề rộng rừng ngập mặn giảm khoảng 70-140 m trong giai đoạn 2006-2014 và khoảng 10-50 m trong giai đoạn 20142020. Kết quả nghiên cứu diễn biến vị trí đường bờ trong nghiên cứu này phù hợp với kết quả trong nghiên cứu [13] với bề rộng xói lở từ 50-100 m. Theo [23], 50-70\% năng lượng sóng sẽ bị tiêu tán bởi $20 \mathrm{~m}$ rừng phòng hộ đầu tiên với chiều sâu cột nước từ 1,9-2,0 $\mathrm{m}$. Khi độ sâu cột nước tăng lên $2,5 \mathrm{~m}$, cần $40 \mathrm{~m}$ rừng ngập mặn để có thể hấp thụ $50 \%$ năng lượng sóng. Trước tình trạng xói lở bờ biển đang xảy ra nghiêm trọng do mất dần diện tích rừng ngập mặn, tỉnh Sóc Trăng đang áp dụng thí điểm giải pháp kè giảm sóng và tạo bãi bằng hai hàng cọc ly tâm đặt cách bờ biển khoảng $170 \mathrm{~m}$ (Hình 1). Nhóm nghiên cứu đang tiến hành quan trắc số liệu sóng và cao độ bãi biển phía trong kè ly tâm để đánh giá khả năng giảm sóng và tạo bãi của tuyến kè này. Một điểm cần chú ý trên Hình 5 là đường bờ có xu hướng dịch chuyển ngang bờ trong khi vẫn giữ nguyên hình dạng, điều này phù hợp với giả thuyết tính toán của [19-20] trong mô hình tính toán thay đổi thể tích bờ biển.

Bảng 3. Số liệu vị trí đường bờ theo không gian và thời gian với đường bờ năm 2006 là đường cơ sở.

\begin{tabular}{|c|c|c|c|c|c|c|c|c|}
\hline \multirow{2}{*}{$\begin{array}{c}\text { Khoảng } \\
\text { cách dọc bò̀ } \\
\text { x (m) }\end{array}$} & \multirow{2}{*}{\multicolumn{2}{|c|}{$\begin{array}{c}\text { Mặt } \\
\text { cắt }\end{array}$}} & \multicolumn{6}{|c|}{ Ngày } \\
\hline & & & $12 / 04 / 2006$ & 08/04/2014 & 09/06/2017 & 09/03/2018 & $15 / 02 / 2019$ & $14 / 11 / 2020$ \\
\hline 0 & $1-1$ & Vị trí & 0 & -80.24 & -94.17 & -99.26 & -107.09 & -115.52 \\
\hline 200 & $2-2$ & đường & 0 & -120.07 & -134.37 & -136.25 & -133.99 & -155.42 \\
\hline
\end{tabular}




\begin{tabular}{|c|c|c|c|c|c|c|c|c|}
\hline \multirow{2}{*}{$\begin{array}{c}\text { Khoảng } \\
\text { cách dọc bò } \\
\text { x (m) }\end{array}$} & \multirow{2}{*}{$\begin{array}{l}\text { Mặt } \\
\text { cắt }\end{array}$} & \multirow{9}{*}{$\begin{array}{c}\text { bờ - y } \\
\text { (m) }\end{array}$} & \multicolumn{6}{|c|}{ Ngày } \\
\hline & & & $12 / 04 / 2006$ & $08 / 04 / 2014$ & 09/06/2017 & 09/03/2018 & $15 / 02 / 2019$ & $14 / 11 / 2020$ \\
\hline 400 & $3-3$ & & 0 & -83.04 & -93.61 & -101.32 & -112.56 & -130.2 \\
\hline 600 & $4-4$ & & 0 & -113.92 & -112.88 & -120.71 & -116.68 & -121.62 \\
\hline 800 & $5-5$ & & 0 & -72.55 & -81.78 & -89.86 & -108.74 & -125.35 \\
\hline 1000 & $6-6$ & & 0 & -138.82 & -147.04 & -150.33 & -151.46 & -176.54 \\
\hline 1200 & $7-7$ & & 0 & -117.14 & -124.56 & -131.95 & -126.64 & -135.42 \\
\hline 1400 & $8-8$ & & 0 & -113.92 & -114.13 & -115.59 & -120.31 & -129.11 \\
\hline 1520 & $9-9$ & & 0 & -154.10 & -159.41 & -161.36 & -151.01 & -147.36 \\
\hline
\end{tabular}

Vận tốc xói bồi tại các mặt cắt dọc theo bờ biển từ cống số 2 đến cống số 3 được trình bày trong Bảng 4 và Hình 6. Có thể nhận thấy bãi biển khu vực nghiên cứu chịu tác động hoàn toàn của xói lở bờ biển với tốc độ xói lớn nhất lên đến $11,68 \mathrm{~m} /$ năm tại mặt cắt $6-6$ (x $=1.000 \mathrm{~m}$ ) và tốc độ xói nhỏ nhất bằng $7,95 \mathrm{~m} /$ năm tại mặt cắt $1-1(\mathrm{x}=0)$. Hệ số xác định $\left(\mathrm{R}^{2}\right)$ của chuỗi dữ liệu vị trí đường bờ tại các mặt cắt đều lớn hơn hoặc bằng 0,8 chứng tỏ sự phù hợp của việc sử dụng mô hình hồi quy tuyến tính trong tính toán vận tốc thay đổi vị trí đường bờ tại khu vực nghiên cứu.

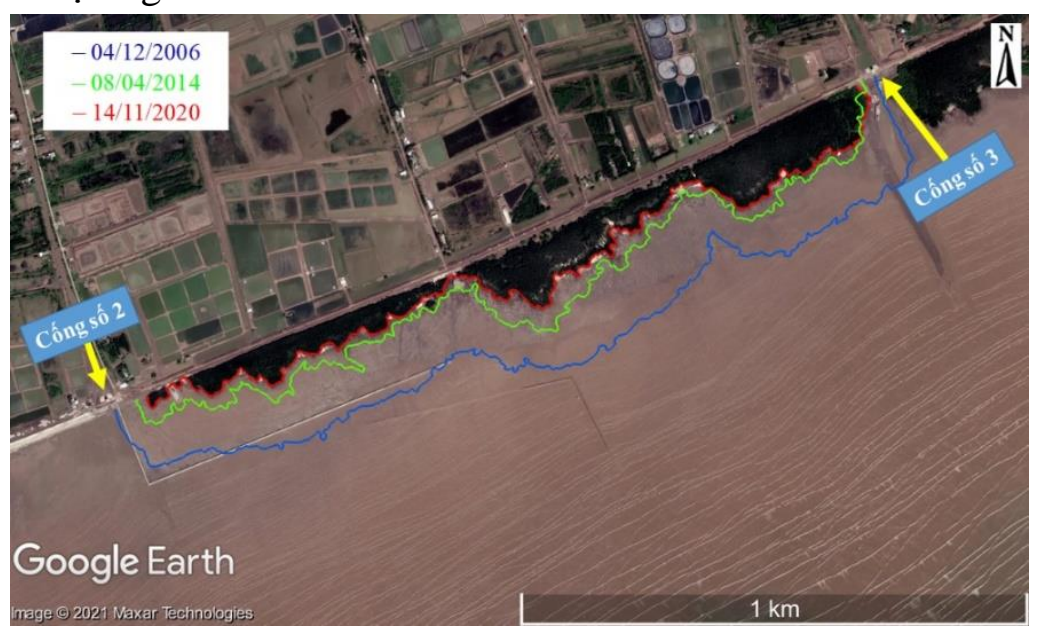

Hình 5. Thay đổi vị trí đường bờ.

Bảng 4. Vận tốc xói bồi đường bờ tại các mặt cắt.

\begin{tabular}{cccc}
\hline Mặt cắt & $\begin{array}{c}\text { Khoảng cách dọc bò̀ } \\
\mathbf{x}(\mathbf{m})\end{array}$ & $\begin{array}{c}\text { Vận tốc thay đổi đường bò̀ } \\
\mathbf{a}(\mathbf{m} / \mathbf{n a ̆ m})\end{array}$ & $\begin{array}{c}\text { Hệ số xác định } \\
\mathbf{R}^{\mathbf{2}}\end{array}$ \\
\hline $1-1$ & 0 & $-7,95$ & 0,98 \\
$2-2$ & 200 & $-10,44$ & 0,94 \\
$3-3$ & 400 & $-8,58$ & 0,98 \\
$4-4$ & 600 & $-8,48$ & 0,86 \\
$5-5$ & 800 & $-8,16$ & 0,97 \\
$6-6$ & 1000 & $-11,68$ & 0,93 \\
$7-7$ & 1200 & $-9,44$ & 0,90 \\
$8-8$ & 1400 & $-8,76$ & 0,89 \\
$9-9$ & 1520 & $-10,75$ & 0,80 \\
\hline
\end{tabular}




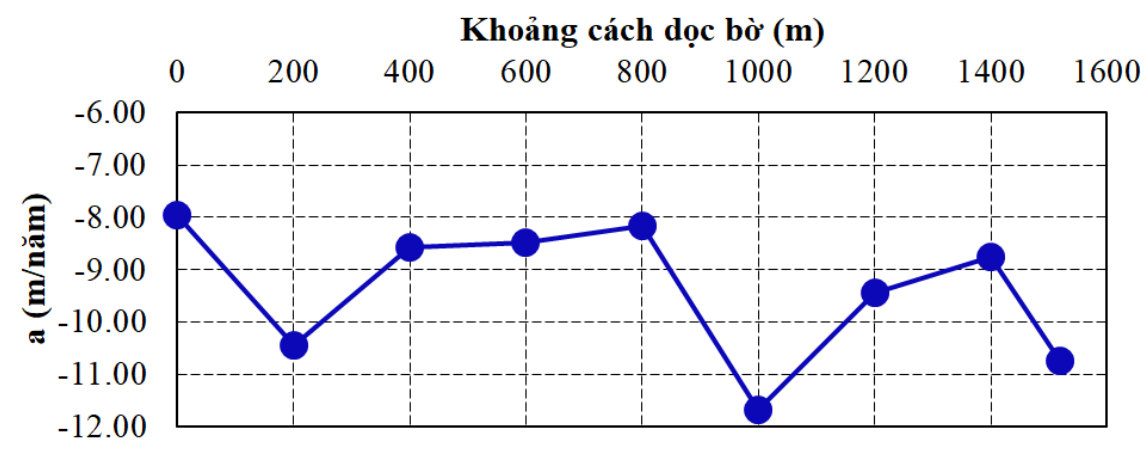

Hình 6. Vận tốc xói bồi tại các mặt cắt.

\subsection{Thay đổi thể tích bãi biển}

Thay đổi thể tích bãi biển giữa các mặt cắt được trình bày trong Bảng 5 và Hình 7. Giá trị thay đổi thể tích bãi biển giữa các mặt cắt được biểu diễn tại trung điểm giữa 2 mặt cắt liên tiếp. Nhìn chung bãi biển khu vực nghiên cứu chịu tác động của xói lở với thể tích suy giảm trong khoảng từ 3.000 đến $7.000 \mathrm{~m}^{3} / \mathrm{năm}$. Giá trị thay đổi thể tích bãi biển tại trí $\mathrm{x}=$ $1460 \mathrm{~m}$ khá nhỏ so với các vị trí còn lại vì khoảng cách giữa 2 mặt cắt cuối cùng chỉ bằng $120 \mathrm{~m}$ trong khi tại các vị trí còn lại khoảng cách giữa 2 mặt cắt liên tiếp đều bằng $200 \mathrm{~m}$. Các kết quả tính toán biến động thể tích bãi biển KVNC có thể được sử dụng để tính toán lưu lượng vận chuyển bùn cát ven bờ. Tuy nhiên, các kết quả trên chỉ phản ảnh biến động trung bình của bãi biển theo năm mà chưa chỉ ra được biến động theo mùa vì hạn chế về số liệu ảnh viễn thám. Trong các nghiên cứu tiếp theo, số liệu sóng thực đo và dòng chảy ven bờ sẽ được sử dụng để đánh giá biến động của bãi biển theo mùa và tương quan giữa biến động thể tích bãi biển với các chế độ sóng theo mùa.

Bảng 5. Vận tốc thay đổi thể tích bãi biển giữa các mặt cắt.

\begin{tabular}{cc}
\hline $\begin{array}{c}\text { Khoảng cách dọc bò̀ } \\
\mathbf{x}(\mathbf{m})\end{array}$ & $\begin{array}{c}\text { Thay đổi thể tích bãi biển } \\
\Delta \mathbf{V}\left(\mathbf{m}^{\mathbf{3}} / \mathbf{n a ̆ m}\right)\end{array}$ \\
\hline 100 & -5.518 \\
300 & -5.707 \\
500 & -5.119 \\
700 & -4.992 \\
900 & -5.953 \\
1100 & -6.338 \\
1300 & -5.460 \\
1460 & -3.512 \\
\hline
\end{tabular}

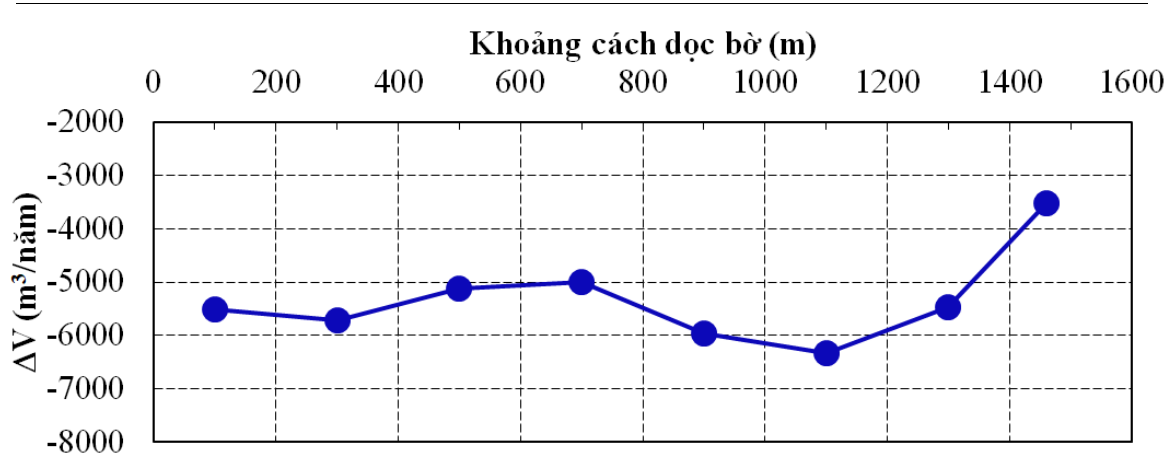

Hình 7. Vận tốc thay đổi thể tích bãi biển giữa các mặt cắt. 


\section{Kết luận}

Ảnh viễn thám và mô hình một đường đã được sử dụng để quan sát diễn biến xói lở một phần đường bờ biển thị xã Vĩnh Châu tỉnh Sóc Trăng và tính toán tốc độ xói bồi của bãi biển.

Kết quả phân tích cho thấy thấy một phần đường bờ biển khu vực thị xã Vĩnh Châu tỉnh Sóc Trăng (từ cống số 2 đến cống số 3) bị xói lở nghiêm trọng trong giai đoạn 2006-2020 với bề rộng rừng ngập mặn suy giảm khoảng 70-140 m giai đoạn 2006-2014 và 10-50 m giai đoạn 2014-2020.

Vận tốc xói lở đường bờ biển lớn nhất bằng 11,68 m/năm.

Sử dụng mô hình một đường, vận tốc suy giảm thể tích bãi biển tại các mặt cắt dọc theo đường bờ biển khu vực nghiên cứu được tính toán dao động trong khoảng 3.000-7.000 $\mathrm{m}^{3} /$ năm.

Kết quả trong bài báo này chỉ dựa trên số liệu phân tích ảnh viễn thám giai đoạn 20062020 với số liệu ảnh hạn chế (chỉ thu thập được 06 ảnh). Trong các nghiên cứu tiếp theo, số liệu về sóng thực đo, địa hình đáy biển khu vực nghiên cứu sẽ được sử dụng để mô phỏng chế độ dòng chảy và vận chuyển bùn cát ven bờ.

Đóng góp của tác giả: Xây dựng ý tưởng nghiên cứu: T.V.T., D.V.D.; Lựa chọn phương pháp nghiên cứu: T.V.T., D.V.D., H.T.C.H., T.T.L.; Xử lý số liệu: T.T.L., T.V.T., L.M.H.; Lấy mẫu: T.T.L., L.M.H., H.T.C.H.; Phân tích mẫu: D.V.D., H.T.C.H., T.T.L.; Viết bản thảo bài báo: T.V.T., D.V.D., H.T.C.H.; Chỉnh sửa bài báo: T.V.T., H.T.C.H.

Lời cam đoan: Tập thể tác giả cam đoan bài báo này là công trình nghiên cứu của tập thể tác giả, chưa được công bố ở đâu, không được sao chép từ những nghiên cứu trước đây; không có sự tranh chấp lợi ích trong nhóm tác giả.

\section{Tài liệu tham khảo}

1. Lawrence, P.L. Natural hazards of shoreline bluff erosion: A case study of horizon view, Lake Huron. Geomorphology 1994, 10(1-4), 65-81.

2. Zuzek, P.J.N.; R.B.; Thieme, S.J.S. Patial and temporal consideration for calculating shoreline change rates in the Great Lakes Basin. In: Byrnes, M.R.; Crowell, M., and Fowler, C. (eds.), Shoreline Mapping and Change Analysis: Technical Considerations and Management Implications. J. Coastal Res. 2003, SI 38, 125-146.

3. Gens, R. Remote sensing of coastlines: Detection, extraction and monitoring. Int. J. Remote Sens. 2010, 31(7), 1819-1836.

4. Elizabeth, H.B.; Ian, L.T. Shoreline Definition and Detection: A Review. J. Coastal Res. 2005, 2005(214), 688-703.

5. Alberico, I.; Cavuoto, G.; Di Fiore, V.; Punzo, M.; Tarallo, D.; Pelosi, N.; Ferraro, L.; Marsella, E. Historical maps and satellite images as tools for shoreline variations and territorial changes assessment: the case study of Volturno Coastal Plain (Southern Italy). J. Coastal Conserv. 2018, 22(5), 919-937.

6. Morton, R.A.; Mark, P.L.; Jeffrey, G.P.; Michael, A.C. Monitoring Beach Changes Using GPS Surveying Techniques. J. Coastal Res. 1993, 9(3), 702-720.

7. Laporte-Fauret, Q.; Marieu, V.; Castelle, B.; Michalet, R.; Bujan, S.; Rosebery, D. Low-Cost UAV for High-Resolution and Large-Scale Coastal Dune Change Monitoring Using Photogrammetry. J. Mar. Sci. Eng. 2019, 7(3), 1-16. 
8. Pianca, C., Holman, R., Siegle, E. Shoreline variability from days to decades: Results of long-term video imaging. J. Geophys. Res. Oceans 2015, 120(3), 2159-2178.

9. Anh, T.K.D.; Sierd de, V.; Marcel, J.F.S. The Estimation and Evaluation of Shoreline Locations, Shoreline-Change Rates, and Coastal Volume Changes Derived from Landsat Images. J. Coastal Res. 2018, 35(1), 56-71.

10. Nghĩa, N.V.; Minh, H.V.T.; Luận, T.C.; Tỷ, T.V. Đánh giá hiệu quả giảm sóng của kè Busadco: trường hợp nghiên cứu tại Biển Đông và Biển Tây tỉnh Cà Mau. Tạp chí xây dưng 2020, 198-205.

11. Pardo-Pascual, J.E.; Almonacid-Caballer, J.; Ruiz, L.A.; Palomar-Vázquez, J. Automatic extraction of shorelines from Landsat TM and ETM+ multi-temporal images with subpixel precision. Remote Sens. Environ. 2012, 123, 1-11.

12. Thịnh, P.T. Rừng ngập mặn ở Sóc Trăng 1965 - 2007. Vùng Ven biển Tỉnh Sóc Trăng. 2011, pp. 60.

13. Tùng, T.T.; Hiền, L.T.; Cát, V.M.; Đoàn, N.K. Nghiên cứu hiện tượng hạ thấp bãi trước đê, từ K0 đến K1+200, tuyến đê biển Bạc Liêu. Khoa học Kỹ thuật Thưy lợi và Môi trường 2015, 50, 83-87.

14. Thuận, N.N.; Tỷ, T.V.; Hừng, T.V.; Hồng, H.T.C.; Nhạn, H.N.; Lâm, T.H.; Duy, Đ.V.; Hải, T.K.; Tuấn, T.V.; Quảng, T.M. Đánh giá hiệu quả của các công trình kè giảm sóng tại bờ biển Tây tỉnh Cà Mau. Tạp chi Khi tượng Thủy văn 2021, 732, 93105.

15. Tiến, N.N.; Cường, Đ.H.; Uu, Đ.V.; Sáo, N.T.; Tuấn, T.A.; Nam, L.Đ. Phân tích biến động đường bờ khu vực bờ biển cửa sông Hậu bằng tư liệu ảnh viễn thám. Tạp chí Khoa học và Công nghệ Biển 2017, 17(4), 386-392.

16. Tình, T.V.; Phong, D.H. Sử dụng ảnh viễn thám và GIS nghiên cứu biến động đường bờ biển khu vực mũi Cà Mau. Tạp chí Khí tương Thủy văn 2017, 12, 35-40.

17. Dolan, R.; Fenster, M.S.; Holme, S.J. Temporal Analysis of Shoreline Recession and Accretion. J. Coastal Res. 1991, 7(3), 723-744.

18. Bình P. T. Giới thiệu mô hình hồi quy tuyến tính. In: Econometrics by Example 2011, pp. 36.

19. Rosati, J.D. Concepts in sediment budgets. J. Coastal Res. 2005, 21(2), 307-322.

20. Rosati, J.D.; Kraus, N.C. Formulation of sediment budgets at inlets. Coastal Eng. Tech. Note 1999, IV-15, pp. 20.

21. Larson, M.; Hanson, H.; Kraus., N.C. Analytical Solutions of One-Line Model for Shoreline Change near Coastal Structures. J. Waterway Port Coastal Ocean Eng. 1997, 123(4), 180-191.

22. Sabatier, F.; Stive, M.; Pons, F. Longshore variation of depth of closure on a microtidal wave-dominated coast. Coastal Eng. 2005, 4, 2327-2339.

23. McIvor, A., Möller, I., Spencer, T., Spalding, M. Reduction of Wind and Swell Waves by Mangroves. Nat. Coastal Prot. Ser. 2012, 40(1), pp. 27.

\section{Temporal variation of shoreline position in Vinh Chau District, Soc Trang Province using satellite image analysis}

\footnotetext{
Le Minh Hau ${ }^{1}$, Huynh Thi Cam Hong ${ }^{2}$, Tran Tuyet Loan², Dinh Van Duy ${ }^{2 *}$, Tran Van $\mathbf{T y} \mathbf{y}^{2}$
} 
${ }^{1}$ Project Management Unit 2 of Soc Trang province; haum4220004@ gstudent.ctu.edu.vn

${ }^{2}$ College of Engineering Technology, Can Tho University; htchong@ctu.edu.vn; loanb1705837@student.ctu.edu.vn; dvduy@ctu.edu.vn; tvty@ctu.edu.vn

\begin{abstract}
Shoreline position data plays an important role in assessing the erosion and accretion of beaches. Among the methods for monitoring beach changes, satellite images analysis appears to be a fast and almost free tool. Hence, this study utilizes the satellite image analysis to assess the temporal variation of shoreline positions in Vinh Chau District, Soc Trang Province from 2006 to 2020. Subsequently, the shoreline change rate (a) and beach volume change $(\Delta \mathrm{V})$ are quantified based on the shoreline positions at each crosssection along the beach. The results show that the beach section from culvert No. 2 to culvert No.3 has been eroded seriously from 2006 to 2020. Specifically, the width of the mangrove forest decreased at the range 70-140 m during the period from 2006 to 2014 and at the range $10-50 \mathrm{~m}$ from 2014 to 2020 . The maximum shoreline change rate reached $11.68 \mathrm{~m} / \mathrm{y}$ and the beach volume change varied from 3,000 to $7,000 \mathrm{~m}^{3} / \mathrm{y}$. The research provides results that could help policy makers to apply approriate solution for coastal erosion mitigation and beach restoration.
\end{abstract}

Keywords: Vinh Chau Soc Trang; Satellite images; Shoreline change rate; Beach volume change; Oneline model. 